MATEC Web of Conferences 6, 04002 (2013)

DOI: $10.1051 /$ matecconf/20130604002

(C) Owned by the authors, published by EDP Sciences, 2013

\title{
Design and performance of a skid-mounted portable compartment fire gas furnace and monitoring system
}

\author{
K. Mueller ${ }^{1}$, Y. Kurama ${ }^{1}$, M. McGinnis² ${ }^{2}$ and M. Lisk ${ }^{2}$ \\ 1 Civil and Environmental Engineering and Earth Sciences, University of Notre Dame, USA \\ 2 Civil Engineering, University of Texas at Tyler, USA
}

\begin{abstract}
A custom, portable natural gas fire furnace was designed and constructed for use at the University of Notre Dame to experimentally investigate the out-of-plane behavior of full-scale reinforced concrete (RC) bearing walls under fire. The unique aspects of this furnace allowed the application of large mechanical loads and non-contact optical response monitoring to be done while subjecting the wall to elevated temperatures. The performance of the experimental furnace, mechanical loading, and response monitoring system is reported using the results from the first two RC wall test specimens.
\end{abstract}

\section{INTRODUCTION}

The need to develop rational performance-based design guidelines for structures under fire has been recently recognized by the engineering community in the United States (U.S.) [1]. In accordance with this need, this research project conducted at the University of Notre Dame in collaboration with the University of Texas at Tyler considers the importance of RC bearing walls on the axial load capacity of tall buildings and the unique challenges from compartment (one-sided) fires. While RC bearing walls are robust and can restrain the spread of fires for multiple hours, the structural load-bearing capacity of the overall system can be greatly affected by one-sided heating and the resulting steep thermal gradients and unsymmetric degradation of the concrete and reinforcing steel across the wall thickness. To investigate these effects, the research is conducting full-scale experiments on RC bearing walls. A unique aspect of the project is the development of a special skid-mounted movable gas furnace that allows for one-sided, localized heating through a user-defined fire time-temperature curve (e.g., the ASTM E119 [2] standard fire). Different from most conventional structural fire testing furnaces, the specimen forms one face of the fire chamber (i.e., specimen is not enclosed within the chamber) representing a compartment fire, thus allowing easier visual inspections, monitoring of behavior, and application of large mechanical loads.

\section{EXPERIMENTAL PROGRAM}

As shown in Fig. 1a, the first two wall specimens tested as part of this project had a thickness of $380 \mathrm{~mm}$ (15 in.) and height of $3.05 \mathrm{~m}(10 \mathrm{ft})$, representing full-scale dimensions from a lower level of a high-rise

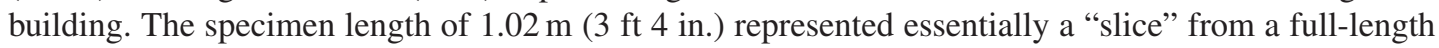
wall to allow for the structure to be tested within the loading capability of the laboratory. The two specimens had identical cross sections (Fig. 1b) with twelve No. 25 (U.S. No. 8) vertical bars and No. 13 (U.S. No. 4) hoops/ties at $230 \mathrm{~mm}$ (9 in.) spacing, modeling typical "boundary" region detailing in RC shear walls. The reinforcing bars were standard ASTM A615M [3] $414 \mathrm{MPa}$ (60 ksi) steel and the concrete was calcareous with a measured compressive strength of around $51 \mathrm{MPa}$ (7.4 ksi) for Specimen

This is an Open Access article distributed under the terms of the Creative Commons Attribution License 2.0, which permits unrestricted use, distribution, and reproduction in any medium, provided the original work is properly cited. 


\section{MATEC Web of Conferences}

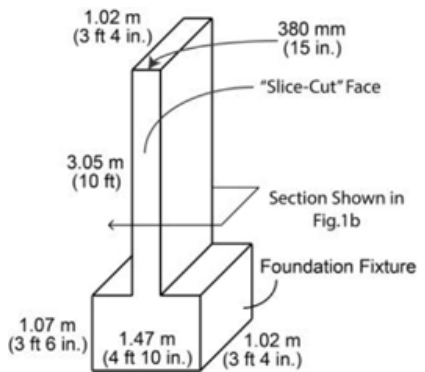

(a)

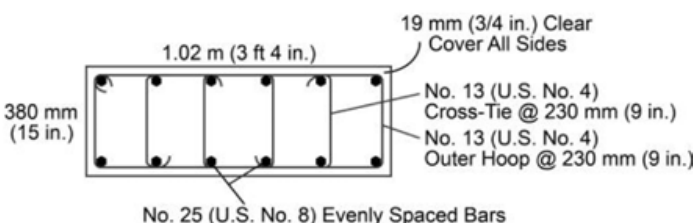

(b)

Figure 1. Specimens 1 and 2 (not to scale): (a) isometric view; (b) cross section view.

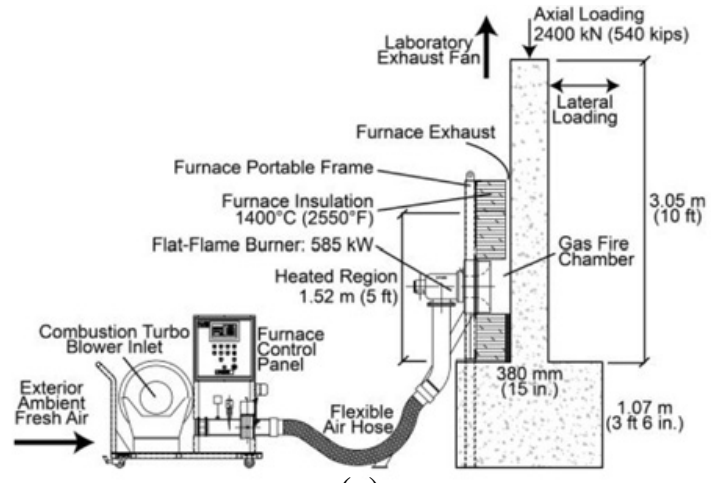

(a)

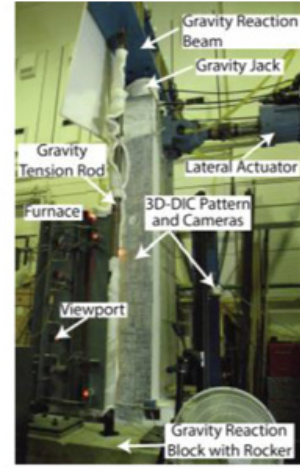

(b)

Figure 2. Test setup: (a) schematic; (b) photograph.

1 and $47 \mathrm{MPa}(6.8 \mathrm{ksi})$ for Specimen 2 on the day that each wall was tested. Specimen 1 was tested at an age of 541 days from casting and Specimen 2 was tested at an age of 973 days. Both specimens were kept indoors in a dry condition from casting until the test day.

The base of each test wall was monolithically supported by a foundation fixture that was tied to a strong floor. To create a compartment style fire, the firing hood (i.e., fire chamber) of the furnace was placed directly in front of one face of the wall (Fig. 2a) and a fire load following the ASTM E119 standard time-temperature (t-T) curve was applied from the top of the foundation fixture over a wall height of $1.52 \mathrm{~m}(5 \mathrm{ft})$. The remaining $1.52 \mathrm{~m}(5 \mathrm{ft})$ height of the wall was outside the fire chamber but was subjected to elevated exhaust temperatures from an opening at the top of the hood. As shown in Fig. 2b, the gravity load system consisted of two hydraulic jacks applying a total load of $2400 \mathrm{kN}$ (540 kips) at the top of each wall specimen throughout the test, resulting in a nominal initial stress of 6.2 $\mathrm{MPa}(0.9 \mathrm{ksi})$ to represent tributary loading. The gravity jacks displaced and rotated together with the top of the wall, thus essentially eliminating second-order $\mathrm{P}-\Delta$ effects. The out-of-plane lateral load system consisted of a $980 \mathrm{kN}$-capacity (220 kip) servo-controlled hydraulic actuator connected $230 \mathrm{~mm}$ ( 9 in.) below the top at mid-length of the wall. Both ends of the actuator were free to rotate, resulting in essentially no rotational or axial restraint to the wall.

The axial load was applied to each wall at room temperature, followed by the fire loading. For Specimen 1, the out-of-plane lateral displacement at the actuator location $[230 \mathrm{~mm}(9 \mathrm{in}$.) below the top] was restrained throughout the fire (i.e., the lateral actuator was operated under displacement control to result in no or negligible out-of-plane movement of the wall at the top). In Specimen 2, a step-wise increased lateral load was applied [4] pushing the wall towards the furnace during the fire (i.e., the 


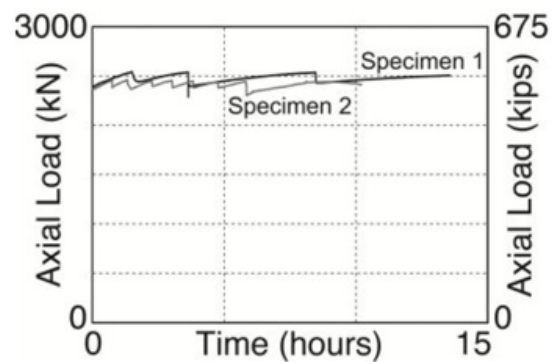

(a)

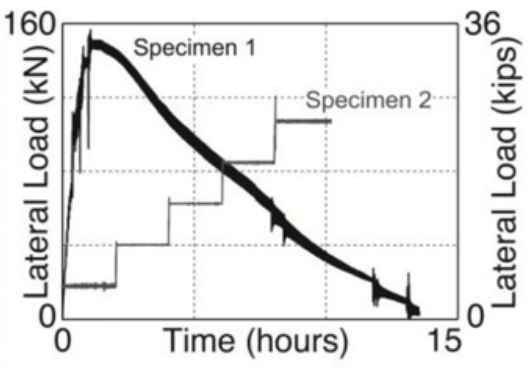

(b)

Figure 3. Measured forces: (a) axial load; (b) out-of-plane lateral load.

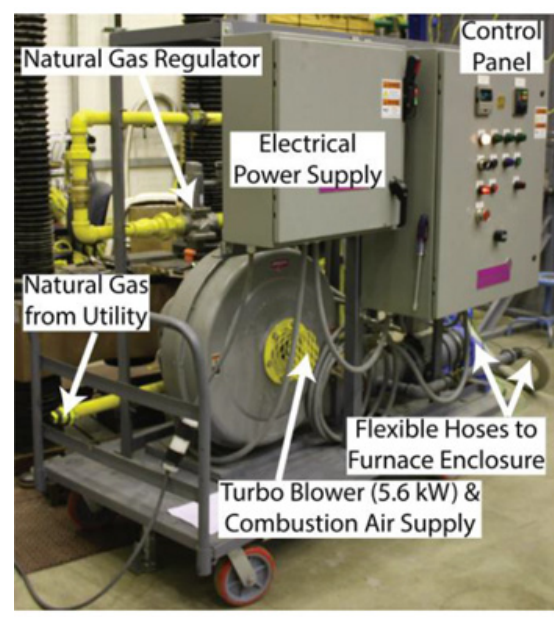

(a)

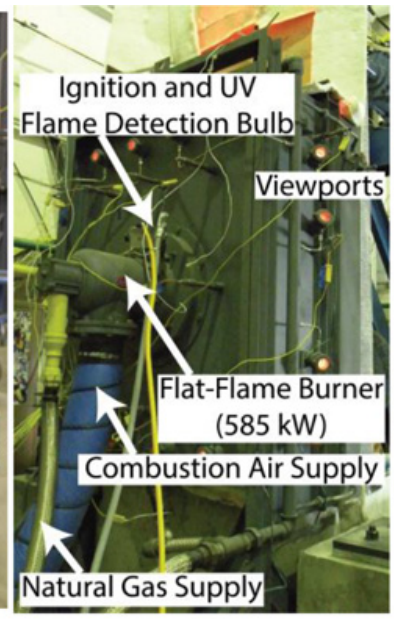

(b)

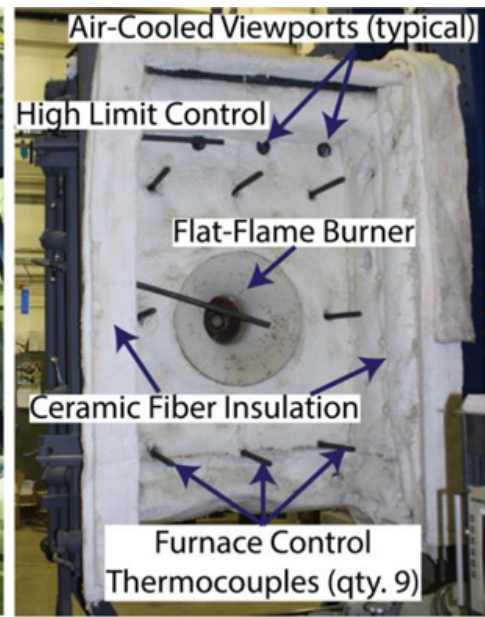

(c)

Figure 4. Two part skid-mounted furnace system: (a) combustion control cart; (b) firing hood; (c) fire chamber.

lateral actuator was operated in force control). Figures $3 \mathrm{a}$ and $3 \mathrm{~b}$ show the total axial load (positive load indicates compression in the wall) and out-of-plane lateral load (positive load indicates compression in the actuator), respectively, applied on the walls up to the end of fire loading, where time is measured from the start of fire (total fire duration of 13.6 and $10.2 \mathrm{hrs}$ for Specimens 1 and 2, respectively). The axial load fluctuated but remained reasonably close to the target $2400 \mathrm{kN}$ (540 kips). At the end of the fire, a reversed-cyclic out-of-plane lateral displacement history was applied at the top of each wall to determine the axial-flexural capacity both immediately after heating as well as after cooling. To fit within the scope of this paper, selected results that demonstrate the performance of the skid-mounted furnace and unique monitoring system are presented herein. More information on the behavior of the specimens, including data from the reverse-cyclic out-of-plane displacement history, can be found in Mueller et al. [4].

\section{CUSTOM, SKID-MOUNTED NATURAL GAS FIRE FURNACE}

As shown in Fig. 4, the custom portable gas fire furnace designed and constructed for this project is a two part skid-mounted system that consists of a portable firing hood and a portable cart for all of the associated combustion control components. The natural gas combustion and control system has a 


\section{MATEC Web of Conferences}

maximum heating capacity of $2.0 \mathrm{MM} \mathrm{Btu} / \mathrm{hr}$ input but is regulated down so that the temperatures can be better controlled to achieve the ASTM E119 time-temperature curve within the relatively small fire

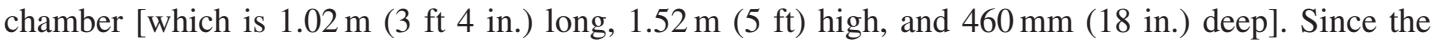
furnace only heats a small volume, it is more energy efficient than a conventional furnace [the natural gas used during the entire fire duration of $10.2 \mathrm{hrs}$ for Specimen 2 was around $7.8 \mathrm{GJ}$ (71.5 therms)]. For future projects, it would be possible to modify the dimensions and geometry of the fire chamber to accommodate other size test specimens. The combustion air blower, fuel train, and control panel is rack mounted on a portable cart with caster wheels and includes the necessary safety shut-off valves, pressure-reducing regulators, low and high pressure switches, metering orifices, etc., to provide a complete natural gas supply train. The firing hood, which houses a flat-flame natural gas burner, is mounted on a steel frame, which is also supplied with lockable caster wheels for easy placement against the test specimen. The entire system requires the connection and disconnection of fuel gas between the fuel gas inlet and the control cart and between the control cart and the firing hood. These connections use flexible gas and air hoses, allowing flexibility in the positioning of the control cart and the firing hood during a test. Adequate separation can be created between the firing hood and the control cart, providing safe operation for laboratory personnel away from the test specimen. Disconnect couplings with spring loaded shutoffs are included for quick disassembly of the components after the test, and both the firing hood and the control cart can be stored away when not in use. The firing hood is weight balanced so that the entire unit can be lifted by an overhead crane.

The flat-flame natural gas burner, which has the capacity to reach temperatures above $1400^{\circ} \mathrm{C}\left(2550^{\circ} \mathrm{F}\right)$, operates at a firing rate of around $585 \mathrm{~kW}$ and distributes the combustion air evenly around the gas stream, creating uniform combustion and a well-defined flame pattern inside the fire chamber. During operation, the control panel regulates the natural gas input flow from the local utility and the natural gas pressure is kept at an adequate level for the burner to operate efficiently within the fire chamber. The controller also regulates the volume of combustion air sent to the burner. Adjusting the combustion air volume adjusts the thermal load in the fire chamber (more air flow yields a larger thermal load), allowing the user to follow a specified time-temperature curve during the test. The combustion air is continuously taken from the fresh, ambient air within the laboratory (Fig. 2a) using a 3500-rpm, $5.6 \mathrm{~kW}$ turbo blower. The blower also preheats the combustion air before sending it to the burner for greater efficiency. The combustion gases not absorbed by the test specimen are released from a narrow opening at the top of the fire chamber into the laboratory space, where a high-capacity ceiling exhaust fan removes the indoor air from the laboratory and pulls fresh exterior air into the laboratory. As shown in Fig. 2a, this continual process ensures that fresh ambient air is always present in the lab for the efficient operation of the furnace.

The temperatures inside the fire chamber are measured using nine symmetrically disposed thermocouples that follow the performance specifics defined in ASTM E119. There is also a highlimit furnace temperature safety cut-off thermocouple that is monitored by the control panel. These ten thermocouples are separate from the thermocouples needed on or within the test specimen. To reduce the fluctuations of the furnace control and high-limit thermocouple readings, a required time-constant of 5-10 minutes is incorporated into the ASTM E119 time-temperature profile. The time constant specifies the time it takes for the furnace thermocouples to read the actual temperatures within the fire chamber (i.e., ASTM E119 specifies a delay in the temperature reading of the furnace thermocouples), which is achieved by covering the thermocouples with ceramic insulation and embedding them within capped Inconel tubes. Thus, the control and high-limit thermocouples are not directly exposed to the air temperatures inside the fire chamber but instead the Inconel material uniformly conducts the heat from the furnace to produce stable temperature measurements within the tube, allowing better control of the furnace. The fire chamber is lined with $305 \mathrm{~mm}$ thick $\left(12\right.$ in.) $1425^{\circ} \mathrm{C}\left(2600^{\circ} \mathrm{F}\right)$ rated ceramic fiber insulation on all interior surfaces. This allows the outside surfaces of the firing hood to remain at relatively low temperatures as compared with the inside temperatures (the outside surface temperatures of the firing hood reached a state that was too hot to touch only at the very end of testing). The firing 


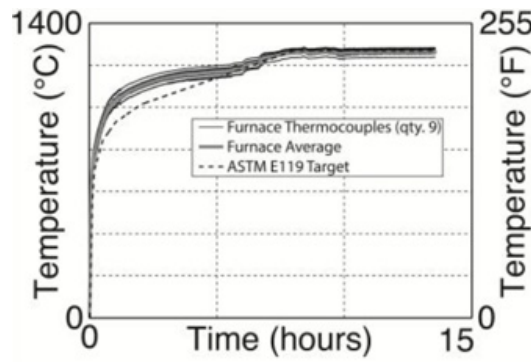

(a)

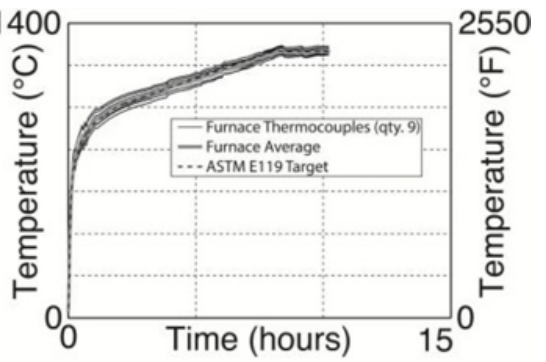

(b)

Figure 5. Furnace air temperatures: (a) specimen 1; (b) specimen 2.

hood utilizes a series of air cooled viewports for the inspection of the heated surface of the test specimen during each test.

\section{RESPONSE MONITORING SYSTEM}

Monitoring of specimen response has posed significant challenges in previous conventional fire experiments where the specimen is fully enclosed within the fire chamber. In comparison, the unique test setup in this project provided access to the unheated surfaces of the test specimens, this allowing unprecedented data to be collected during each test. The measurement system included displacement transducers, inclinometers, strain gauges, thermocouples, and load cells. Additionally, digital image correlation (DIC) and infrared thermography were used on selected faces of the wall to gather full-field surface deformation (strain) and temperature data. While both of these techniques are non-contact and thus, in principle, could be applied through the glass viewports of a conventional furnace, the images are distorted by the flow of hot gasses inside the fire chamber. In the current project, only selected surfaces of each specimen outside the fire chamber were monitored, thus, eliminating this limitation. In digital image correlation [5, 6], a random pattern is applied to the monitored surfaces and a pair of cameras is used to capture stereo pairs of photographs of the pattern before and after load events (Fig. 2b). The digital images are divided into regions that are several pixels square, called facets.

Then, these facets are tracked through an image series using pattern recognition and photogrammetric triangulation principles, thus yielding essentially full-field surface displacements and strains of the field of view (FOV). The accuracy of DIC scales somewhat linearly with the FOV. For the cameras and FOV used herein, the displacement accuracy can be conservatively stated as \pm 15 microns. The thermal imaging camera used in this project functions with a mid-range infrared ( 7.5 to $13 \mu \mathrm{m}$ ) focal plane array un-cooled micro-bolometer sensor and can measure a thermal range of -20 to $+1200^{\circ} \mathrm{C}\left(-4\right.$ to $\left.+2192^{\circ} \mathrm{F}\right)$ at an accuracy of $\pm 2 \%$ of the reading or better for the temperature regimes considered herein. The use of one-sided access (OSA) nuclear magnetic resonance (NMR) imaging to measure moisture distributions through the cover thickness of the walls is also being explored for the future specimens to be tested as part of this project.

\section{THERMAL RESPONSE}

Figs. 5a and 5b show the air temperatures measured by the nine ASTM E119 thermocouples placed within the fire chamber, together with the average temperature from these 9 thermocouples and the ASTM E119 target time-temperature curve. It can be seen that the furnace air temperatures followed the target ASTM time-temperature curve closely except for some overshoot in the early stages of the test for Specimen 1 (this overshoot occurred due to a large initial combustion-firing rate, which was corrected in 


\section{MATEC Web of Conferences}

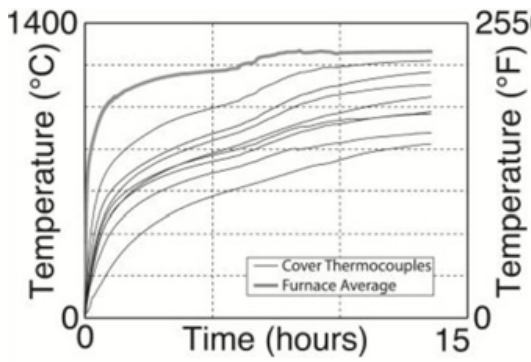

(a)

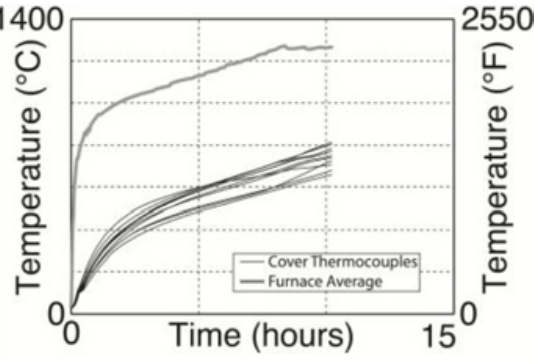

(b)

Figure 6. Interior cover concrete temperatures: (a) specimen 1; (b) specimen 2.

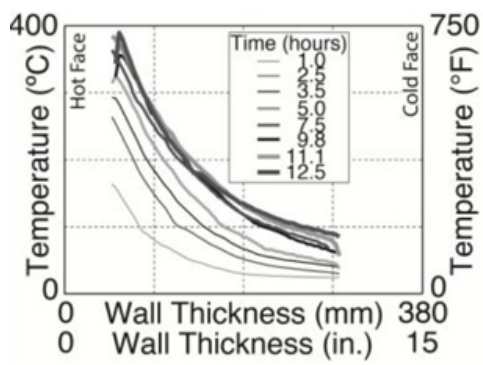

(a)

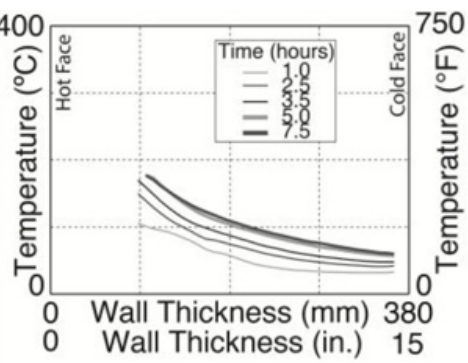

(b)

Figure 7. Surface temperatures over "slice-cut" face: (a) specimen 1; (b) specimen 2.

Specimen 2). The 9 thermocouples generally measured very similar temperatures with little fluctuation, indicating that the air temperatures inside the fire chamber were reasonably uniform within the enclosed volume.

Figs. $6 \mathrm{a}$ and $6 \mathrm{~b}$ show the corresponding interior cover concrete temperatures of Specimens 1 and 2 , respectively, at a depth of $25 \mathrm{~mm}$ (1 in.) from the heated face. These temperatures were measured

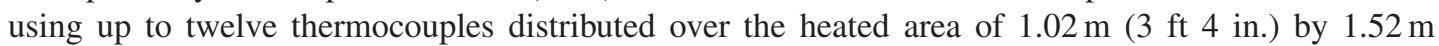
$(5 \mathrm{ft})$ ]. Since the individual interior cover concrete temperatures show no significant jumps, it can be deduced that spalling of the concrete cover did not occur during fire loading, which was also confirmed through the furnace viewports. However, much smaller temperatures were measured by the cover concrete thermocouples in Specimen 2 than in Specimen 1, which is not consistent with the furnace air temperatures that were reasonably similar between the two tests (with the exception of the overshoot during the testing of Specimen 1). The internal temperatures in Specimen 2 also showed much smaller variability. While the exact differences for these differences and deviations are not known, one possibility is the shifting of the cover thermocouples inward during the concrete casting. Prior to casting, all of the internal thermocouples in both walls were tied to a thin fishing line (to minimize unintentional heat transfer) that spanned between the reinforcing bar mats on the hot and cold faces of the wall. While care was exercised to securely tie the thermocouples to the fishing wire and to tie the fishing wire to the available bars, the thermocouples may have shifted inward during the concrete placement, thus measuring lower temperatures at locations deeper than the intended $25 \mathrm{~mm}$ (1 in.) depth from the heated face.

Finally, Figs. 7a and 7b show the exterior surface temperatures over the thickness of each specimen on the "slice-cut" face (end face in Fig. 1a), which was monitored using infrared thermography. The measured temperatures were essentially constant over the height of the heated region; and thus, the infrared thermography results are shown along a horizontal cut at a representative height (i.e., 
(a)

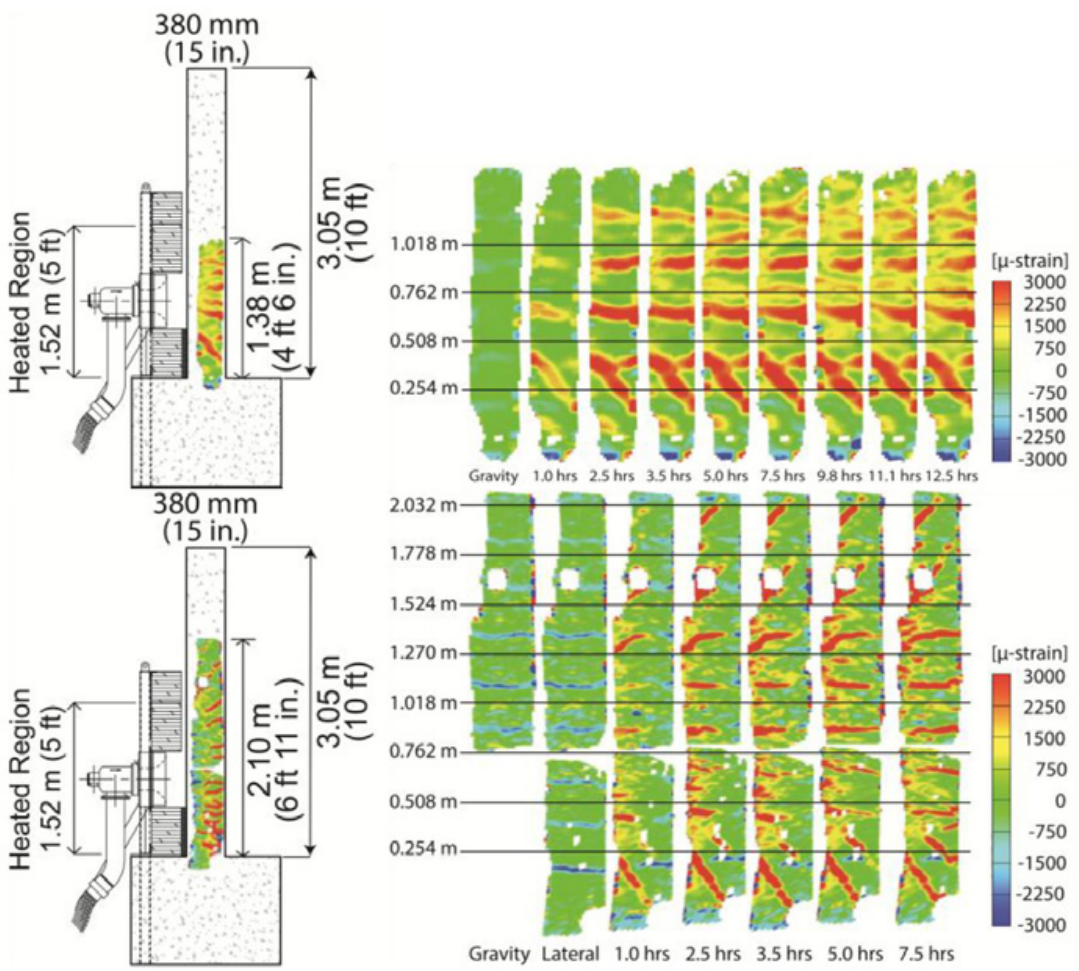

Figure 8. Axial strains: (a) specimen 1; (b) specimen 2.

the thermography temperatures are not averages). Because of heat loss through surface convection, the infrared thermography temperatures were of smaller magnitude than the internal temperatures of the wall concrete, which can be found in Mueller et al. [4]. There was a steep temperature gradient through the thickness of Specimen 1, as would be expected for through thickness heat transfer. However, the measured surface temperatures on the slice-cut face of Specimen 2 were considerably smaller than those for Specimen 1 and also showed a much smaller gradient. While the lower surface temperatures in Specimen 2 seem to be consistent with the lower temperatures measured by the internal cover thermocouples in Fig. 6, the infrared thermography data cannot be explained by the possible shifting of the thermocouples. Rather, the differences between the slice-cut surface temperatures of the two walls could have occurred due to differences in the ambient air flux and air temperatures over the monitored surface during each test.

\section{DEFORMATION RESPONSE}

Figs. 8a and 8b show the axial strains from the DIC data on the monitored slice-cut surface of Specimens 1 and 2, respectively, at various stages during the fire loading. The measured strains are the total strains from coupled thermal and mechanical effects. The leftmost image in each figure shows the extent of the field of view (FOV) on the slice-cut face. The DIC system was able to capture the initiation and location of the cracks [red (dark) shaded regions in the strain plots] with accuracy. Note that these red (dark) shaded regions are not indicative of the actual crack widths. A prominent shear crack developed at the base of Specimen 1 due to the large shear force (Fig. 3b) caused by the restrained boundary condition at the top of the wall. Through-thickness cracking occurred throughout the FOV and the overall strain field became more tensile as the fire duration increased. A similar shear crack also developed at the base 


\section{MATEC Web of Conferences}

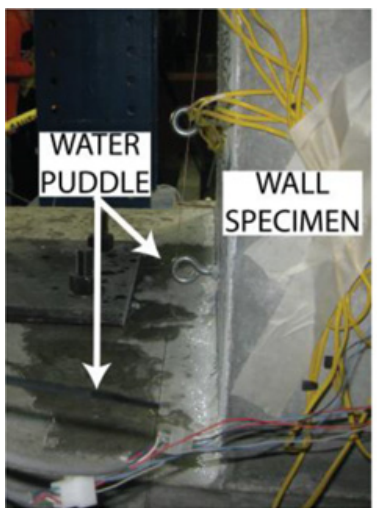

(a)

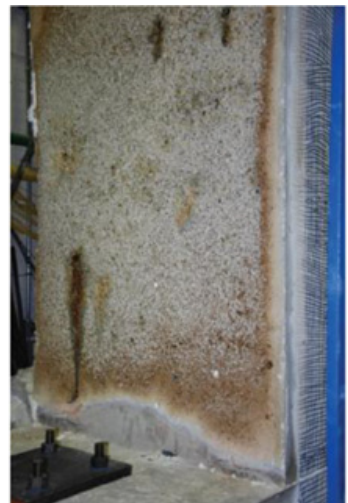

(b)

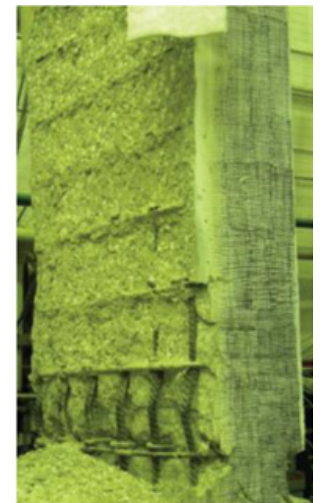

(c)

Figure 9. Concrete spalling: (a) water puddle on foundation; (b) caramelization on hot face; (c) spalling after reversed-cyclic load.

of Specimen 2. However, unlike Specimen 1, the cracks starting from the fire face in Specimen 2 did not become through-thickness cracks until a much longer fire exposure. Specimen 2 also experienced closure of the cracks on the hot face and opening of the cracks on the cold face as the wall started displacing back towards the fire during the later stages of the test. As shown in Fig. 1b, both walls were reinforced with transverse cross-ties through the thickness, representing typical boundary region detailing. However, the web regions of RC walls in practice would typically not include transverse reinforcement, and according to Section 14.3.4 of ACI 318-11 [7], cross ties would not be needed in walls less than $254 \mathrm{~mm}$ (10 in.) thick. The development of a large shear crack at the base of the specimens indicates that walls in practice may need to be reinforced with transverse through-thickness ties to prevent shear failure in the event of a fire.

\section{CONCRETE SPALLING}

No noticeable concrete spalling occurred during the fire loading of either specimen. Thus, the concrete cover continued to provide insulation to the reinforcement in each test. Cracking of the concrete allowed considerable amounts of water and steam to escape from the walls [the amount of water was large enough to form puddles on the laboratory floor and the top of the foundation fixture (Fig. 9a)]. Without substantial pore pressure, explosive spalling did not occur. The hot face of Specimen 1 "caramelized" (Fig. 9b) from the fire and would easily come off upon touching. The subsequent reversed-cyclic lateral load test resulted in the cover concrete on the entire heated face to powderize and fall off, as shown in Fig. 9c for Specimen 2.

\section{ONGOING WORK AND CONCLUSIONS}

The two full-scale RC bearing wall tests described in this paper demonstrate that the moveable gas fire furnace that was designed and constructed for this project allowed complex loading and monitoring systems to be used in the presence of elevated temperatures applied on the walls. The flat-flame burner resulted in uniform temperatures inside the fire chamber. Non-contact optical measurements were successfully used to capture full-field surface strain and temperature data. The internal concrete temperature measurements were affected by the possible shifting of the embedded thermocouples. The ambient air flux and air temperatures on the unheated surfaces may have affected the thermal boundary conditions on the exterior surfaces of the walls. The test results demonstrate that RC bearing walls 
are indeed robust structures that can withstand long periods of time under one-sided fire. However, if a floor slab or other structural component is restraining the out-of-plane displacements, a substantial lateral force can develop due to the thermal bowing of the wall, resulting in a large shear crack across the wall thickness. Additional tests are underway to investigate the effects of important parameters such as reduced wall thickness, eccentric axial load, increased initial axial stress, wall reinforcement, and higher strength concrete. A unique aspect of the upcoming tests is the use of one-sided access (OSA) nuclear magnetic resonance (NMR) imaging to measure moisture distributions over a depth of $25 \mathrm{~mm}$ ( $1 \mathrm{in}$.) from selected unheated surfaces of the walls. This is intended to capture the effects of fire induced concrete cracking on the moisture movement within the cover thickness, without the limitations of embedded moisture probes which perturb the measurement field and provide only discrete point data. Ongoing work in this project also includes numerical analyses of the test specimens and development of structural fire design methodologies for RC bearing walls.

This project at the University of Notre Dame, Indiana was funded by the U.S. National Science Foundation (NSF) under Grant No. CMMI 0800356, together with an EAGER project at the University of Texas at Tyler under Grant No. CMMI 1049577. The support of the current NSF Program Director Dr. K.I. Mehta and former NSF Program Director Dr. M.P. Singh is gratefully acknowledged. The opinions, findings, and conclusions expressed in the paper are those of the authors and do not necessarily reflect the views of the NSF.

\section{References}

[1] NIST, "Final Report on the Collapse of the World Trade Center Towers," National Institute of Standards and Technology, September 2005.

[2] ASTM, "Standard Test Methods for Fire Tests of Building Construction and Materials," ASTM E119, 2012.

[3] ASTM, "Standard Specification for Deformed and Plain Carbon-Steel Bars for Concrete Reinforcement," ASTM A615/A615M, 2012.

[4] Mueller, K., Kurama, Y., and McGinnis, M., "Out-of-Plane Behavior of Two RC Bearing Walls under Fire," $1^{\text {st }}$ International Performance-based and Life-cycle Structural Engineering Conference, Hong Kong, China, 2012.

[5] McGinnis, M., Mueller, K., Kurama, Y., and Graham, K., "RC Bearing Walls Subjected to Elevated Temperatures," ASCE Structures Congress, April 2011, pp. 439-450.

[6] McGinnis, M., Pessiki, S., and Turker, H., "Application of 3D Digital Image Correlation to the Core-Drilling Method," Experimental Mechanics, V. 45, No. 4, 2005, pp. 359-367.

[7] ACI Committee 318, "Building Code Requirements for Structural Concrete (ACI 318-11) and Commentary," American Concrete Institute, Farmington Hills, MI, 2011. 